\title{
A Cross-Sectional Study of Electronic Cigarette Use Among Chinese Adult Populations in Four Cities of China. Part I. Questionnaire Survey *
}

\author{
by \\ Ping-ping Shang ${ }^{1}$, Ge Zhao ${ }^{1}$, Xiang $\mathrm{Li}^{1}$, Chen-feng Hua ${ }^{1}$, Yi-chun Zhang ${ }^{2}$, Jun-wei Zhao ${ }^{1}$, Sheng Wang ${ }^{1}$, \\ Pei-jian Sun ${ }^{1}$, Jun-wei Guo ${ }^{1}$, Mei-juan Fan ${ }^{1}$, Ji-zhao Guo ${ }^{1}$, Sai-jing Zheng ${ }^{2}$, Li-ning Pan ${ }^{1}$, Cheng-wei Lu ${ }^{2}$, \\ Fu-wei Xie ${ }^{l}$, and Gui-xin Peng ${ }^{3}$ \\ 1 Zhengzhou Tobacco Research Institute, CNTC, Zhengzhou City, Henan Province, P.R. China \\ 2 Shanghai New Tobacco Product Research Institute, CNTC, Shanghai, P.R. China \\ ${ }^{3}$ China Tobacco Henan Industrial Co. Ltd., CNTC, Zhengzhou City, Henan Province, P.R. China
}

\section{SUMMARY}

The use of electronic cigarettes (ECs) has grown exponentially over the past few years in China. To obtain the basic information of Chinese EC users, a questionnaire survey was performed to collect the data that describe characteristics of study populations, including daily usage, consumption preference, and risk perception. Volunteers were recruited from Beijing, Shanghai, Guangzhou, and Shenzhen cities of China. In total, among the 511 participants that were included in the analysis, 491 participants $(95 \%)$ used refillable ECs in the past 3 months. There was a strong association between EC use and traditional cigarette smoking. The majority of participants were dual users and the number of cigarettes smoked decreased with the use of ECs. After using an EC, 20.7\% of conventional cigarette smokers attempted to quit smoking. Young people were the primary users across all geographic locations. Specifically, the daily usage for the participants who were 18-39 years old, was higher than those over 40 years old. The majority of participants $(59.9 \%)$ preferred fruit flavors and $57.8 \%$ of them used $1-5 \mathrm{mg} / \mathrm{mL}$ nicotine-concentration liquids. Most EC users are motived to quit smoking, and $74.6 \%$ claimed that the ECs had no irritant effect on the oral cavity. A total of $50.5 \%$ of family members of the study participants reported an improvement of health status while the participants used ECs instead of traditional cigarettes. Overall, the results of this Chinese survey indicate that the per-day cigarette consumption of the dual users decreased whereas their proportion of smokers of low-"tar" cigarettes increased. [Contrib. Tob. Nicotine Res. 30 (2021) 138-148]

KEY WORDS: electronic cigarette; questionnaire; survey

\section{ZUSAMMENFASSUNG}

Die Nutzung elektronischer Zigaretten (EZ) ist in China in den letzten Jahren exponentiell angestiegen. Um grundlegende Informationen $\mathrm{zu}$ chinesischen EZ-Nutzern $\mathrm{zu}$ erhalten, wurde mithilfe eines Fragebogens eine Umfrage durchgeführt, bei der zur Beschreibung der Merkmale der Studienpopulation Daten wie tägliche Nutzung, Konsumpräferenzen und Risikowahrnehmung erhoben wurden. Die Probanden wurden in den chinesischen Städten Beijing, Shanghai, Guangzhou und Shenzhen rekrutiert. Insgesamt hatten von den 511 in die Analyse eingeschlossenen Teilnehmern 491 (95\%) in den letzten drei Monaten nachfüllbare E-Zigaretten verwendet. Es bestand eine enge 
Assoziation zwischen der Nutzung elektronischer Zigaretten und dem Rauchen herkömmlicher Zigaretten. Die Mehrheit der Teilnehmer waren Doppelnutzer, die sowohl herkömmliche als auch E-Zigaretten konsumierten, wobei die Anzahl der gerauchten Zigaretten mit der Nutzung von E-Zigaretten abnahm. Nachdem sie mit der Nutzung von E-Zigaretten begonnen hatten, versuchten 20,7\% der Raucher konventioneller Zigaretten, das Rauchen aufzugeben. An allen geographischen Standorten waren die Hauptnutzer junge Menschen. Insbesondere war die tägliche Nutzung bei den Teilnehmern in der Altersgruppe der 18- bis 39-Jährigen höher als bei den über 40-Jährigen. Die Mehrheit der Teilnehmer (59,9\%) bevorzugte Fruchtaromen und 57,8\% nutzten Liquids mit einer Nikotinkonzentration von $1-5 \mathrm{mg} / \mathrm{mL}$. Die meisten Nutzer von E-Zigaretten waren motiviert, mit dem Rauchen aufzuhören, und $74,6 \%$ gaben an, dass die E-Zigaretten keine Reizungen im Mundraum verursachten. Insgesamt berichteten 50,5\% der Angehörigen von EZ-Nutzern, dass sich deren Gesundheitszustand mit der Nutzung von E-Zigaretten anstelle von herkömmlichen Zigaretten verbessert hatte. Insgesamt zeigen die Ergebnisse dieser chinesischen Untersuchung, dass die Anzahl der pro Tag gerauchten Zigaretten in der Gruppe der Doppelnutzer abnahm, während der Anteil der Raucher von Zigaretten mit niedrigem Teergehalt in derselben Gruppe zunahm. [Contrib. Tob. Nicotine Res. 30 (2021) 138-148]

\section{RESUME}

Au cours des dernières années, l'usage des cigarettes électroniques a progressé de façon exponentielle en Chine. Afin de récolter des informations essentielles au sujet des fumeurs chinois d'e-cigarettes, un sondage basé sur un questionnaire fut mené afin de relever des données descriptives des caractéristiques des populations étudiées, telles que la consommation journalière, les préférences de fumage et la perception du risque. Des bénévoles furent recrutés dans les villes chinoises de Beijing, Shanghai, Guangzhou et Shenzhen. Au total, parmi les 511 individus inclus dans l'échantillon, 491 personnes (95\%) avaient utilisé des cigarettes électroniques rechargeables au cours des trois mois précédents. L'étude révéla un lien fort entre l'utilisation de la cigarette électronique et le fumage de cigarettes traditionnelles. La majorité des personnes interrogées étaient des utilisateurs des deux dispositifs et le nombre de cigarettes fumées décroissait en cas de recours aux cigarettes électroniques. Après être passés à l'ecigarette, $20,7 \%$ des fumeurs de cigarettes traditionnelles tentèrent d'arrêter de fumer. Les jeunes étaient les principaux utilisateurs, indépendamment du lieu géographique. Plus précisément, la consommation quotidienne parmi les sondés âgés de 18 à 39 ans était supérieure à celle des plus de 40 ans. La majorité des personnes interrogées (59,9\%) préféraient les saveurs fruitées et 57,8\% d'entre elles utilisaient des liquides dont la concentration en nicotine s'élevait à $1-5 \mathrm{mg} / \mathrm{mL}$. La plupart des fumeurs d'e-cigarettes sont motivés à arrêter de fumer et $74,6 \%$ affirmèrent que les cigarettes électroniques ne produisaient aucun effet irritant sur leur cavité buccale. Un total de 50,5\% des proches des utilisateurs de cigarettes indiquèrent une amélioration de leur état de santé après l'abandon de la cigarette traditionnelle au profit de la cigarette électronique. Dans l'ensemble, les résultats issus de ce sondage chinois révélèrent que le nombre de cigarettes fumées au quotidien par les utilisateurs des deux dispositifs était en recul et que la proportion de fumeurs préférant les cigarettes «à faible teneur en goudron» augmentait parmi les utilisateurs des deux dispositifs. [Contrib. Tob. Nicotine Res. 30 (2021) 138-148]

\section{INTRODUCTION}

An electronic cigarette (EC), also known as an electronic nicotine delivery system (ENDS), is a device that uses a battery power source to atomize specialized liquid in order to transfer nicotine, and other substances, to the respiratory system by means of electronic heating. A Chinese pharmacist invented the first e-cigarette product in 2003. One year later, ECs emerged in the Chinese market and then rapidly expanded worldwide (1). Large-scale use in China was observable since 2015. At present, ECs in the Chinese market are predominately sold through internet and retail stores in high-income and middle-income cities.

Under the global anti-smoking legislation, the usage of ECs has increased exponentially (2). Research on the prevalence and cognitive status of users of ECs and the effects on users' health have been performed in Europe, America, and Canada. The results suggest that the usage of ECs is strongly associated with the use of traditional cigarettes $(3,4)$. In addition, a United States study demonstrated that the availability of ECs could also expand the market of tobacco products. Over the years, the total number of young people using both kinds of tobacco products has increased, instead of simply replacing traditional cigarettes with ECs (5).

An investigation of EC users among smokers in Beijing found that $12.8 \%$ (122 participants) of traditional cigarette smokers had used ECs for some time in the past (6). Among the 122 smokers who used ECs, the majority (84\%) thought that ECs were not addictive or less addictive than cigarettes, and more than $70 \%$ considered that ECs were healthier and less risky than cigarettes. Li et al. conducted a survey in urban residents in Tianjin and found that $2.3 \%$ (45 participants) used ECs. Overall, the percentage of EC users who tried to quit smoking in the past 12 months was significantly higher than those who had never used ECs (7). There is a lack of comprehensive studies to evaluate the EC-user behavior in Chinese populations. To better understand the current prevalence of EC use in Chinese populations, this study surveyed EC users by using a questionnaire addressing characteristics of the participants, consumption behavior, user history and status of tobacco products, user perception and the influence on the EC users' personal and families' health.

\section{METHODS}

Representative area and volunteer recruitment

Four cities were selected to launch the project, which were selected based on the Baidu search indices (24). Notably, 
these cities were the top four cities for EC usage in the period between October 2015 and October 2017. EC users were recruited both through online advertisements and EC experience stores.

\section{Participant requirements in the study}

In order to participate, volunteers must have an EC usage history for 3 months past with a frequency of at least 3 days per week. Moreover, participants were required to be over 18 years old, without serious cardiovascular or respiratory diseases, and they had to sign their informed consent prior to in-person interviews. The exclusion criteria included: a) illegal drugs abuse; b) major depressive disorders or other psychiatric disorders; c) severe cardiovascular diseases, chronic obstructive pulmonary disease, lung cancer or other diagnosed tumors, and severe physiological deformities. Women were excluded if they were breastfeeding or pregnant.

\section{Questionnaire}

On the basis of multiple considerations, like extensive consultation with epidemiologic researchers, market salesmen, product researchers, and development personnel, a large number of studies were consulted. Based on previous studies, we designed our survey questionnaire for ECusing participants, which included the following elements: (i) Characteristics including age, gender, education, occupation and other information; (ii) Consumption behavior including duration of EC use, device type (cigarette-like: disposable and one-off use; tank: replacement of EC liquid cartridges and reusable batteries; customizer: refillable with e-liquids to supplement EC vapor), nicotine concentration, taste, usage frequency, priority factors; (iii) History and status of tobacco products, former daily use of traditional cigarettes, span of time in which traditional cigarettes were consumed, uptake or reduction of smoking after EC use; (iv) Perception and reasons for use, method of understanding, harm perception, smoking cessation, influence on surrounding people; (v) ECs influence on the users' personal and family health, irritation of the mouth, changes in the respiratory tract, changes in physical health, and attitude of family and friends towards ECs.

The study was reviewed by and received ethics clearance from the Public Health Institute of the University of Zhengzhou. The participants' voluntary informed consent, confidentiality, and good research practice were followed throughout the investigation. The data of the questionnaire survey was collected through in-person interviews. In detail, the photos, videos of EC devices, and information from volunteers were all collected at the interview site.

\section{Statistical analysis}

All analyses were conducted using SPSS 22.0 Demo software (SSPS Inc., Chicago, IL, USA). Continuous variables were defined as: "EC use times per day", "Amount of liquid per day". Data are expressed as mean \pm SD. Quantitative data were analyzed by single factor ANOVA with the Levene test to test homogeneity of variance. When variance was homogeneous, the Bonferroni method was used for multiple comparisons of the mean of each group. If variance was uneven, Dunnett's T3 test was used for multiple comparisons. Chi-square analysis was used to examine differences in categorical variables, such as flavor preferences, nicotine concentrations, duration of EC use, using frequency during the past 30 days, and the proportion of the dual users who smoked cigarettes containing different concentrations of "tar" before and after using ECs.

\section{RESULTS}

\section{Target areas and populations}

Through the geographical distribution of the Baidu search index and the city ranking of the Baidu search index, four cities including Beijing, Shanghai, Guangzhou, and Shenzhen, were marked as high EC usage cities. In this study, 18,970 people were invited through internet shops and local EC stores. Ultimately 527 people met the research conditions, and 511 people participated in the survey. Among those who did not participate were many who were reluctant to engage in all requested procedures prior to the start. The final group consisted of $82,123,149$, and 157 volunteers from Beijing, Shanghai, Guangzhou, and Shenzhen, respectively. The invitation/success rate of e-cigarette users was only $2.8 \%$. The main factor affecting the success rate was the low popularity of e-cigarettes in China at the time.

\section{Sociodemographic characteristics}

The baseline sociodemographic characteristics of the participants are displayed in Table 1. EC users were disproportionately young, with $47.6 \%$ between 18 and 29 years old. The majority of EC users was male, with an overall ratio of $90.6 \%$. Variance ratios based on gender suggest that the city of Shanghai had the largest percentage of women users among the four cities, which was about $15.4 \%$. As to the participants' education level, it was found that the proportion of participants with a bachelor degree, an associate degree, or high school graduation was $45.2 \%$, $36.0 \%$ and $16.8 \%$, respectively. According to the occupational distribution, the number of participants working in the general staff of a company and the middle or senior management were relatively higher than others, which were $28.4 \%$ and $23.3 \%$ respectively. $36.9 \%$ of the participants were students in Shenzhen. Figure 1 shows in more detail the differences in occupational distribution across cities and the total.

\section{Behavior}

An investigation of the type of EC used in the four cities showed that the majority of users $(n=491,96.1 \%)$ chose the cartomized device (shown in Table 2). Only 15 and 5 participants, respectively, chose the refillable tank device and disposable cigarette-like ECs. In the group of users of the customized device, age groups were used to analyze and compare consumer behaviors. Statistical analysis and distribution of group data determined that there was no difference in daily usage of ECs and EC liquid among all age groups (shown in Table 3 ). 


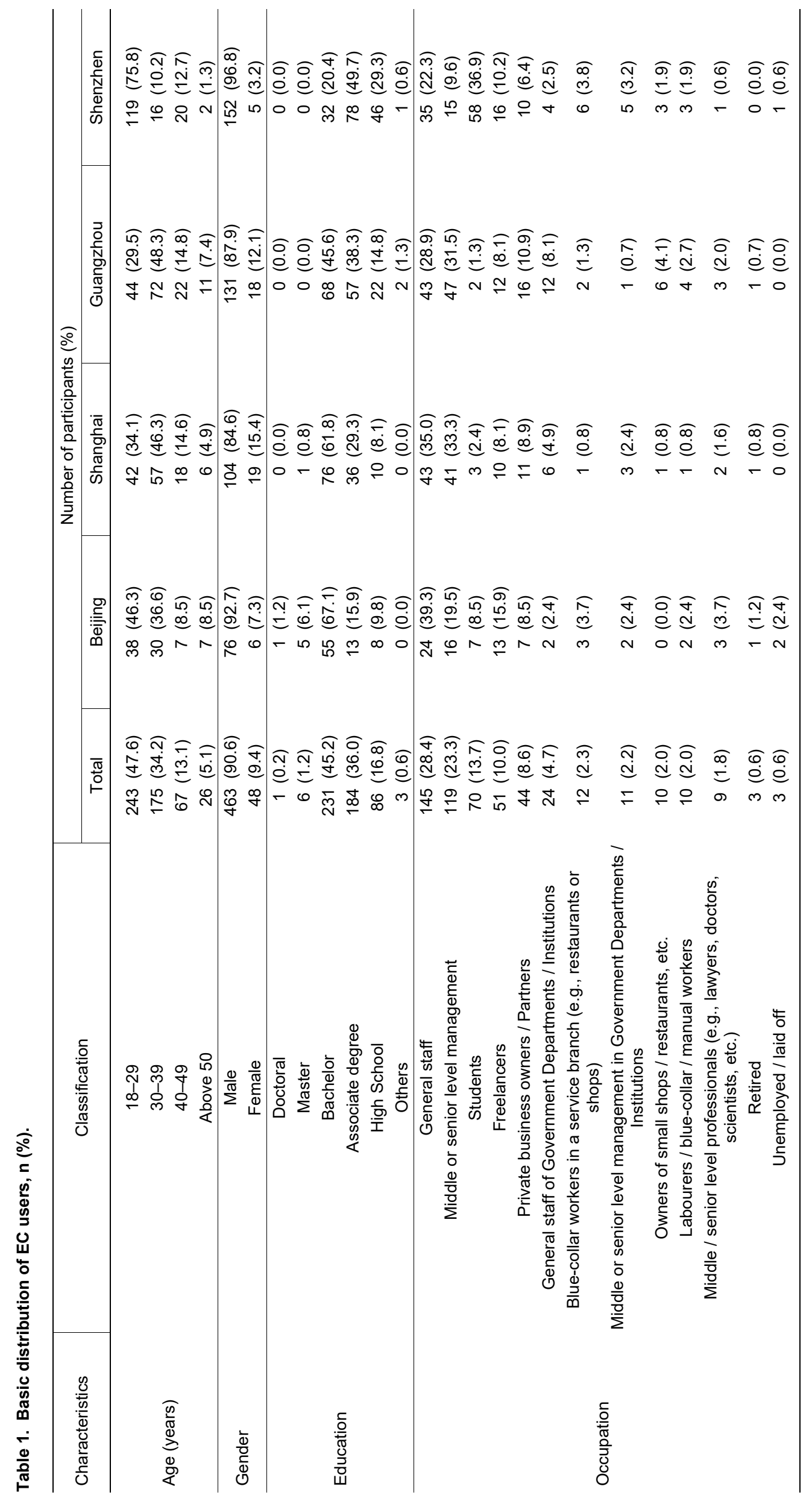




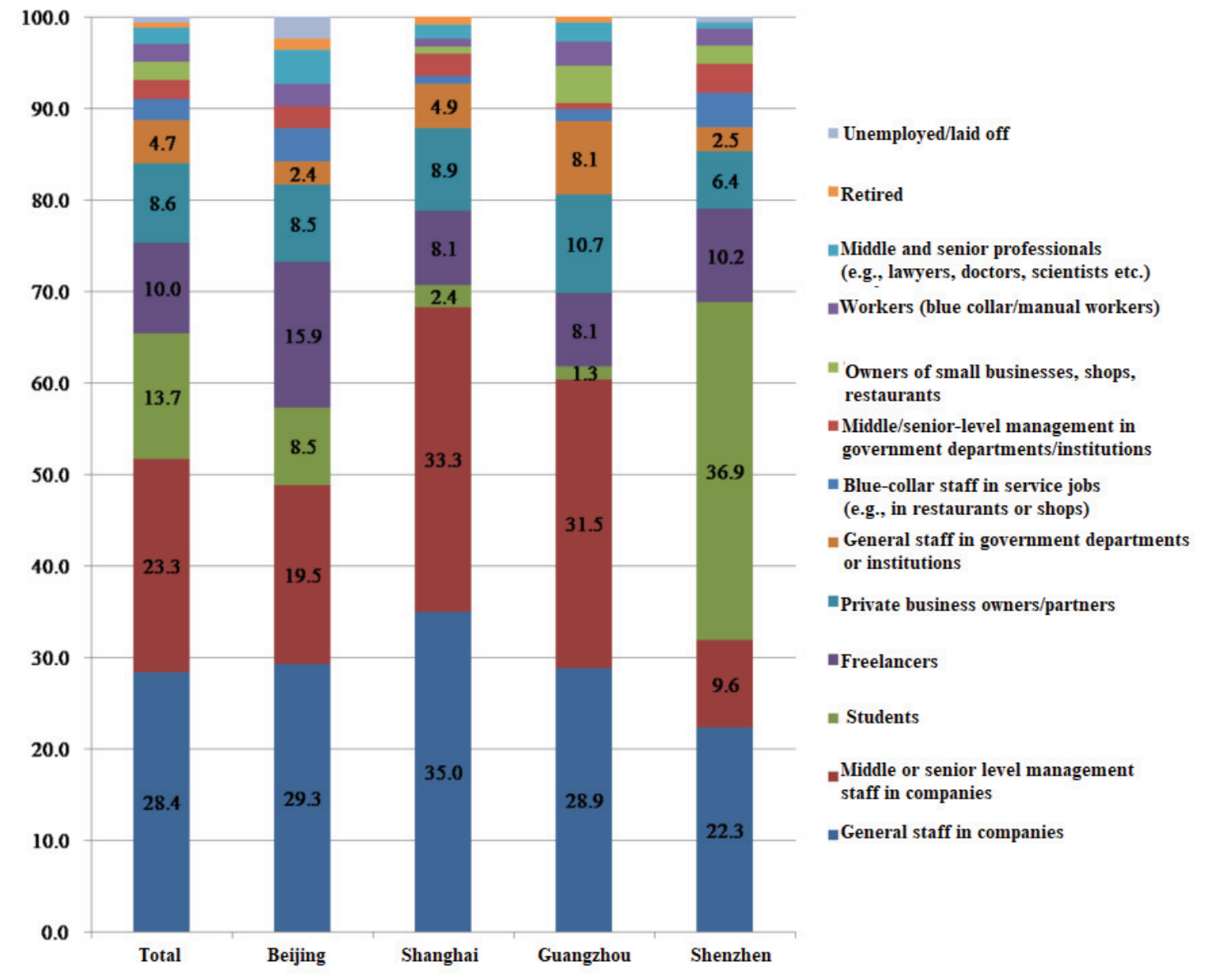

Figure 1. Occupational distribution in cities and total (\%).

Table 2. Types of e-cigarettes used in the four cities.

\begin{tabular}{l|c|c|c|c|c|}
\hline \multirow{2}{*}{ Classification } & \multicolumn{5}{c|}{ Number of participants (\%) } \\
\cline { 2 - 6 } & Total & Beijing & Shanghai & Guangzhou & Shenzhen \\
\hline \multirow{2}{*}{ Cartomized } & $491(96.1)$ & $80(97.6)$ & $113(91.9)$ & $147(98.7)$ & $151(96.2)$ \\
Tank & $15(2.9)$ & $2(2.4)$ & $9(7.3)$ & $2(1.3)$ & $2(1.3)$ \\
Disposable & $5(1.0)$ & $0(0)$ & $1(0.8)$ & $0(0)$ & $4(2.5)$ \\
\hline
\end{tabular}

Table 3. Daily usage of ECs and EC liquid by age groups.

\begin{tabular}{l|c|c}
\hline User behaviour & $\begin{array}{c}\text { Age group } \\
\text { (years) }\end{array}$ & $\overline{\mathrm{X}} \pm \mathrm{SD}$ \\
\hline & $18-29$ & $88.3 \pm 88.3$ \\
$\begin{array}{l}\text { Frequency per day } \\
\text { (times/day) }\end{array}$ & $30-39$ & $83.0 \pm 88.1$ \\
& $40-49$ & $64.0 \pm 75.2$ \\
& Over 50 & $62.0 \pm 73.0$ \\
Volume of EC & $18-29$ & $7.2 \pm 7.3$ \\
liquid per day & $30-39$ & $6.0 \pm 6.0$ \\
(mL/day) & $40-49$ & $3.4 \pm 4.4^{*}$ \\
& Over 50 & $2.5 \pm 1.8^{*}$ \\
\hline
\end{tabular}

* There is a statistical difference in the age groups of $18-29$ and $30-39$ years.
Compared with the age groups of "18-29 years" and "30-39 years", the amounts of liquid used per day in the age groups of "40-49 years" and "over 50 years" were lower $(\mathrm{p}<0.01)$.

Flavor preferences were grouped into five categories: Fruit - fresh fruit such as bananas and apples $(n=294,59.9 \%)$; tobacco (imitation CHUNGHWA, Furogwang, Yuxi, or similar) $(\mathrm{n}=101,20.6 \%)$; cigar flavor $(\mathrm{n}=7,1.4 \%)$; chocolate flavor $(\mathrm{n}=5,1.0 \%)$; menthol flavor $(\mathrm{n}=62$, $12.6 \%$ ); or other (flavors not readily classified by the above mentioned categories, such as fresh milk, Red Bull, ice cream, Coke, Yakult, or red wine) $(n=22,4.5 \%)$. Most EC users surveyed were found to prefer fruit-flavored products. Flavor preference was observed to be further stratified by age group. The majority of participants in the age group of 18-29 years preferred fruit flavors $(n=173$, $73.3 \%)$. 


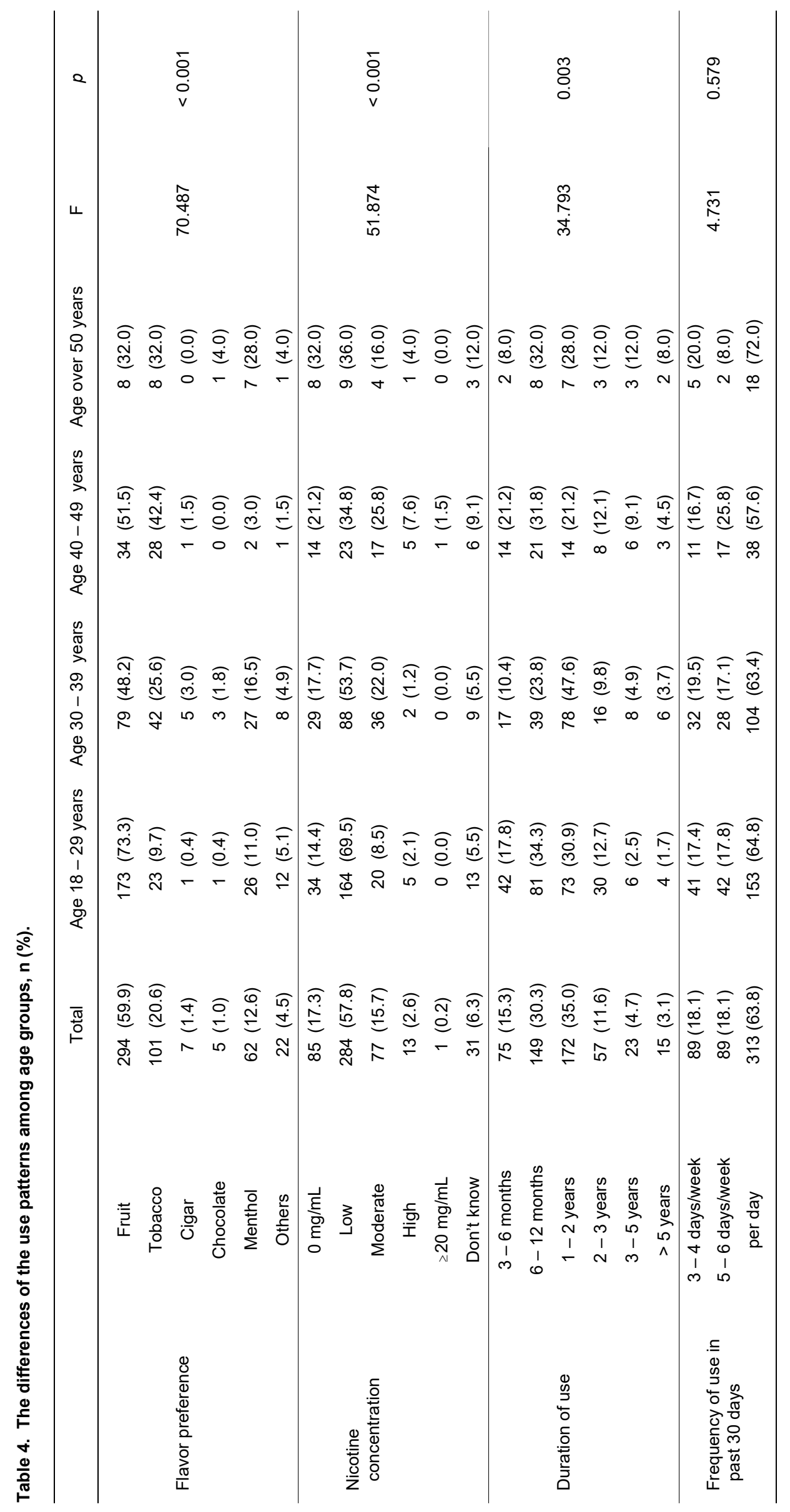


However, preference for fruit flavors decreased among the 30-39 year-old participants $(n=79,48.2 \%)$. The concentration of nicotine was divided into 5 grades: nicotine-free; low: $1-5 \mathrm{mg} / \mathrm{mL}(0.1-0.5 \%)$; moderate: $6-11 \mathrm{mg} / \mathrm{mL}$ (0.6\%-1.1\%); high: $12-20 \mathrm{mg} / \mathrm{mL}(1.2 \%-2.0 \%)$; and $>20$ $\mathrm{mg} / \mathrm{mL}$. A majority $(\mathrm{n}=284,57.8 \%)$ preferred low nicotine concentrations. Only one user reported a preference for an EC containing $>20 \mathrm{mg} / \mathrm{mL}$ nicotine. EC use duration of the majority of users ranged from 6 months to 2 years $(65.3 \%)$. Most participants $(n=313,63.8 \%)$ used ECs every day, with no significant differences across all age groups in the usage frequency in the past 30 days. (Table 4).

\section{Usage status of tobacco products}

Table 5 displays the current use of the different tobacco products. In Table 6 the term "Product usage" was individually separated into (i) users who only used ECs ( $n=137$, $26.8 \%$ ), including non smokers and former smokers, (ii) users who simultaneously smoked conventional cigarettes ( $\mathrm{n}=374,73.2 \%$ ) termed as "dual use". In the group of ECs-only use, $80.3 \%$ of the participants were cigarette smokers. This means that smoking may affect the use of ecigarettes (Table 6). In the group of dual users, there were a lot of participants $(88.2 \%)$ who previously smoked before starting to use ECs. It should also be noted that $11.8 \%$ of the participants never smoked before using ECs.

And Table 6 furthermore shows that some participants will smoke cigarettes after using ECs.

On average, after using an EC, $20.7 \%$ of conventional cigarette smokers attempted to quit smoking. Geographically, this value varied somewhat in Beijing (25.0\%), Shanghai (19.4\%), Guangzhou (17.4\%), and Shenzhen (22.5\%). Successful smoking cessation within one month was at $27.9 \%$. And the time interval necessary for quitting smoking in different cities proved quite different. In Beijing, 43.8\% of EC-using participants quit smoking within a month whereas $45.2 \%$ of EC consumers of Shenzhen quit smoking within 3 months (Table 7).

Daily cigarette consumption of the dual users before and after using ECs are shown in Table 8. According to the data of the four cities and in total, the number of cigarettes smoked per day decreased significantly after the participants' starting to use ECs. The use of e-cigarettes affected the choice of cigarettes smoked by dual users concerning "tar" content. After using e-cigarettes, the proportion of people smoking low "tar" cigarettes increased from $16.4 \%$ to $30.6 \%$ (Table 9). There was a significant increase in the number of dual users smoking cigarettes with "tar" yields below $6 \mathrm{mg}\left(X^{2}=34.064, p<0.001\right)$. The proportion of people smoking low "tar" cigarettes was the same in each city.

Table 5. Usage status of tobacco products, $\mathbf{n}(\%)$.

\begin{tabular}{l|c|c|c|c|c}
\hline Product usage & Total & Beijing & Shanghai & Guangzhou & Shenzhen \\
\hline EC only & $137(26.8)$ & $21(25.6)$ & $31(25.2)$ & $42(28.2)$ & $43(27.4)$ \\
Dual usage & $374(73.2)$ & $61(74.4)$ & $92(74.8)$ & $107(71.8)$ & $114(72.6)$ \\
\hline
\end{tabular}

Table 6. The history of cigarette smoking for EC-only users and dual users, $\mathbf{n}(\%)$.

\begin{tabular}{ll|c|c|c|c|c}
\hline User of: & User history/status & Total & Beijing & Shanghai & Guangzhou & Shenzhen \\
\hline \multirow{3}{*}{ ECs only } & Always using ECs only & $101(19.7)$ & $12(14.3)$ & $32(25.8)$ & $43(28.6)$ & $15(9.3)$ \\
& Smoker before using ECs only & $410(80.3)$ & $70(85.7)$ & $91(74.2)$ & $106(71.4)$ & $142(90.7)$ \\
& Smoker before using ECs & $451(88.2)$ & $65(78.7)$ & $100(81.5)$ & $139(93.5)$ & $147(93.9)$ \\
\multirow{2}{*}{ Dual usage } & Nonsmoker before using ECs & $60(11.8)$ & $17(21.3)$ & $23(18.5)$ & $10(6.5)$ & $10(6.1)$ \\
\cline { 2 - 5 } & & &
\end{tabular}

Table 7. Smoking cessation among EC users (\%).

\begin{tabular}{l|c|c|c|c|c}
\hline Smoking cessation within & Total (\%) & Beijing (\%) & Shanghai (\%) & Guangzhou (\%) & Shenzhen (\%) \\
\hline$\leq 1$ month & $30(27.9)$ & $9(43.8)$ & $8(33.3)$ & $2(9.5)$ & $10(29.0)$ \\
$>1 \leq 3$ months & $28(26.7)$ & $1(6.3)$ & $7(27.8)$ & $4(14.3)$ & $16(45.2)$ \\
$>3 \leq 6$ months & $20(18.6)$ & $4(18.8)$ & $3(11.1)$ & $10(38.1)$ & $3(9.7)$ \\
$>6 \leq 12$ months & $14(12.8)$ & $3(12.5)$ & $4(16.7)$ & $6(23.8)$ & $1(3.2)$ \\
$>1 \leq 2$ years & $7(7.0)$ & $1(6.3)$ & $3(11.1)$ & $1(4.8)$ & $2(6.5)$ \\
$>2 \leq 3$ years & $6(5.8)$ & $3(12.5)$ & $0(0.0)$ & $1(4.8)$ & $2(6.5)$ \\
$>3$ years & $1(1.2)$ & $0(0.0)$ & $0(0.0)$ & $1(4.8)$ & $0(0.0)$ \\
\hline
\end{tabular}


Table 8. Cig/day of dual users before and after using ECs.

\begin{tabular}{l|cc|c|c}
\hline \multirow{2}{*}{ Total } & \multicolumn{2}{|c|}{ Cigarettes/day $(\overline{\mathrm{X}} \pm \mathrm{SD})$} & \multirow{2}{*}{$t$} & $p$ \\
\cline { 2 - 3 } & $14.20 \pm 8.85$ & $8.23 \pm 4.95$ & $14.08<0.001$ \\
Beijing & $18.67 \pm 11.19$ & $9.27 \pm 4.95$ & $5.40<0.001$ \\
Shanghai & $14.97 \pm 8.43$ & $8.20 \pm 4.95$ & $4.65<0.001$ \\
Guangzhou & $18.08 \pm 8.44$ & $9.60 \pm 5.29$ & $9.95<0.001$ \\
Shenzhen & $14.07 \pm 7.62$ & $8.04 \pm 4.42$ & $9.16<0.001$ \\
\hline
\end{tabular}

\section{EC perception}

The reasons for initiating EC use were analyzed in Table 10. Some reasons for use initiation were reported as: "to quit smoking", "to reduce smoke-related exposure to family members", "to avoid smoking bans in public places", "the choice of multiple flavors in ECs", "to pursue fashion or curiosity", "economic reasons", "to make smoke rings", "to pursue a healthy lifestyle", or "living abroad for a long time". Participants were permitted to provide more than one reason for use initiation. Most people stated that quitting smoking and reducing the exposure of family members to cigarette smoke were their most important reasons for starting EC use. The proportions were 74.8\% and $49.9 \%$ respectively. $69.5 \%$ of the participants came into contact with ECs through relatives, friends, or colleagues for the first time. Other ways to get to know e-cigarettes are traditional advertising, articles, online advertisements, EC experience stores or shops, and WeChat circles. More than half of the participating EC users $(51.3 \%)$ believe there is no harm at all in ECs although 9.4\% participants thought ECs are less harmful than traditional cigarettes. But $88.6 \%$ of the participants were unsure whether ECs were less harmful than cigarettes. A majority of participants $(60.5 \%)$ considered that using ECs could help to quit smoking and them using ECs began as a way to stop smoking cigarettes. When using ECs in public places, $46.8 \%$ of the users thought that it would not cause health impacts on the surrounding non-smokers through second- hand vaping. But $31.0 \%$ of the participants considered that using ECs may affect nearby non-smokers. Participants stated that they gained information on health effects of ECs from different sources: by consulting professional books or scientific literature $(28.4 \%)$, from the internet $(27.3 \%)$, or from information provided by acquaintances $(29.8 \%)$. The majority of the participants $(62.7 \%)$ expressed an openness to communicate frequently with others about the products, flavors, usage, and related information.

\section{Effects on health and family}

As shown in Table 11, a small number of participants experienced side effects. Reported side effects included: irritation to the mouth $(21.5 \%)$ and adverse respiratory effects $(56.6 \%)$. After using ECs for 3 months, $42.3 \%$ of the participants felt better about their overall health as defined by factors such as: weight, sleep quality, memory, or sense of smell. Simultaneously $50.5 \%$ of the participants claimed that their family and friends supported their use of ECs.

\section{DISCUSSION}

Since the emergence of ECs on the market, there has been widespread interest and attention from traditional cigarette smokers. However, Chinese domestic attention to the use of ECs is generally low and the research on ECs is rare at present. This study is the first questionnaire-based investigation among EC users in China.

Many participants were classified as dual users who still smoked cigarettes while also using ECs; only $19.7 \%$ of the participants surveyed were non-smokers prior to use. ECs are popular among young people in Beijing, Shanghai, Guangzhou, and Shenzhen predominately. This may be because young people are generally better educated and receptive to new things.

One Canadian study targeted the previous 30-day use of students in grades 9-12 (2). This Canadian study showed that there was a strong correlation between the use of ECs and cigarette smoking.

Table 9. Proportion of dual users before and after using ECs by cigarette "tar" bands, $\mathbf{n}(\%)$.

\begin{tabular}{|c|c|c|c|c|c|c|}
\hline & & \multicolumn{3}{|c|}{$\begin{array}{l}\text { The number of dual users smoking cigarettes containing } \\
\text { different concentrations of "tar" }\end{array}$} & \multirow[t]{2}{*}{$x^{2}$} & \multirow[t]{2}{*}{$p$} \\
\hline & & $<6$ & $6-8$ & $9-11$ & & \\
\hline \multirow{2}{*}{ Total } & before using ECs & $84(16.4)$ & $132(25.8)$ & $268(52.4)$ & \multirow{2}{*}{34.064} & \multirow{2}{*}{0.000} \\
\hline & after using ECs & $156(30.6)$ & $158(30.9)$ & $197(38.5)$ & & \\
\hline \multirow{2}{*}{ Beijing } & before using ECs & $22(27.1)$ & $17(20.8)$ & $43(52.1)$ & \multirow{2}{*}{6.650} & \multirow{2}{*}{0.036} \\
\hline & after using ECs & $34(41.7)$ & $21(25.0)$ & 27 (33.3) & & \\
\hline \multirow{2}{*}{ Shanghai } & before using ECs & $18(14.7)$ & $39(32.0)$ & $59(48.0)$ & \multirow{2}{*}{9.996} & \multirow{2}{*}{0.007} \\
\hline & after using ECs & $34(28.0)$ & $49(40.0)$ & $39(32.0)$ & & \\
\hline \multirow{2}{*}{ Guangzhou } & before using ECs & $19(13.0)$ & $46(31.0)$ & $77(52.0)$ & \multirow{2}{*}{11.047} & \multirow{2}{*}{0.004} \\
\hline & after using ECs & $37(25.0)$ & 58 (39.0) & $54(36.0)$ & & \\
\hline \multirow{2}{*}{ Shenzhen } & before using ECs & $25(15.9)$ & $29(18.7)$ & $88(56.11)$ & \multirow{2}{*}{9.269} & \multirow{2}{*}{0.010} \\
\hline & after using ECs & $51(32.7)$ & 31 (19.6) & $75(47.7)$ & & \\
\hline
\end{tabular}


Table 10. Perception of ECs among the users.

\begin{tabular}{|c|c|c|}
\hline E-cigarette perception & & Proportion $\mathrm{n}(\%)$ \\
\hline \multirow{9}{*}{ Reasons given for initiating EC use } & To quit smoking & $382(74.8)$ \\
\hline & To reduce the exposure to cigarette smoke of family members & $255(49.9)$ \\
\hline & To avoid a smoking ban in public places & $221(43.2)$ \\
\hline & Multiple flavors in ECs & $204(39.9)$ \\
\hline & For reasons of fashion or curiosity & $198(38.7)$ \\
\hline & Economic reasons & $9(1.8)$ \\
\hline & To make smoke rings & $2(0.4)$ \\
\hline & To pursue a healthy lifestyle & $2(0.4)$ \\
\hline & Due to living abroad for a long time & $1(0.2)$ \\
\hline \multirow{5}{*}{ First contact with EC } & Introduced by relatives, friends, or colleagues & $355(69.5)$ \\
\hline & Advertising in print articles or online & $65(12.7)$ \\
\hline & EC experience store or EC shop & $60(11.7)$ \\
\hline & WeChat friends circle & $24(4.7)$ \\
\hline & Outdoor advertising & $7(1.4)$ \\
\hline \multirow{3}{*}{ ECs are less harmful than traditional cigarettes } & Yes & $48(9.4)$ \\
\hline & No & $11(2.2)$ \\
\hline & I don't know & $453(88.6)$ \\
\hline \multirow{3}{*}{ Is there any risk of harm from ECs? } & Yes & $38(7.5)$ \\
\hline & No & $262(51.3)$ \\
\hline & I don't know & $210(41.1)$ \\
\hline \multirow{3}{*}{ Ability to quit smoking by using ECs } & I can quit & $309(60.5)$ \\
\hline & I can't quit & $69(13.6)$ \\
\hline & I don't know & $132(25.9)$ \\
\hline \multirow{3}{*}{$\begin{array}{l}\text { Does using ECs have an effect on people } \\
\text { around you who don't smoke }\end{array}$} & Yes & $158(31.0)$ \\
\hline & No & $239(46.8)$ \\
\hline & I don't know & $113(22.2)$ \\
\hline \multirow{4}{*}{$\begin{array}{l}\text { The most persuasive channel for "information } \\
\text { on the health effects of ECs" }\end{array}$} & Consulting professional books or scientific literature & $145(28.4)$ \\
\hline & Searching for information on the Internet & $140(27.3)$ \\
\hline & Introduction by acquaintances & $152(29.8)$ \\
\hline & Related materials provided by retail stores & $74(14.5)$ \\
\hline \multirow{4}{*}{$\begin{array}{l}\text { Channels to communicate on products, taste, } \\
\text { smoking and other related information with } \\
\text { other consumers who use ECs }\end{array}$} & Friends and colleagues who use ECs & $320(62.7)$ \\
\hline & EC-related BBS* and WeChat groups & $74(14.5)$ \\
\hline & EC experience store & $94(18.3)$ \\
\hline & No communication & $23(4.5)$ \\
\hline
\end{tabular}

* BBS: Bulletin Board System

Table 11. Health effects and family response reported by EC users.

\begin{tabular}{l|rr}
\hline Health effects & & Proportion $\mathrm{n}(\%)$ \\
\hline & & $110(21.5)$ \\
Irritating to the mouth & Yes & $381(74.6)$ \\
& I don't know & $20(3.9)$ \\
\hline Adverse respiratory effects & Better & $289(56.6)$ \\
(e.g. pharyngitis, cough, irritation, etc.) & No change & $218(42.7)$ \\
& Worse & $4(0.8)$ \\
\hline $\begin{array}{l}\text { Changes in body and body functions } \\
\text { (e.g. weight, sleep quality, memory, sense of }\end{array}$ & Better & $216(42.3)$ \\
smell etc.) after using ECs for 3 months & No change & $291(56.9)$ \\
\hline & Worse & $4(0.8)$ \\
Attitudes of families and friends towards the & Supportive & $258(50.5)$ \\
use of ECs & Adverse & $25(4.9)$ \\
\end{tabular}


Although most adult smokers reported they were using ECs to quit smoking or to reduce their cigarette smoking, there were also about $20 \%$ of young people aged 15-19 who also used ECs. LEE et al. conducted a survey of reasons for and frequency of EC use among young people aged 13-18 years, in South Korea (8). The survey showed that young smokers believe that ECs can facilitate withdrawal from cigarette smoking.

DAI and HAO conducted a study on the use of scented ECs among middle and high school students in the United States (9). The study found that the use of flavored ECs could increase the risk of initiation to smoking among teens and young adults with no prior history of smoking. These studies all focused on young people, and demonstrated the relationship between socio-demographic characteristics and EC use.

LI et al. also demonstrated that the rate of EC use among the group aged $25-44$ years $(59.23 \%)$ was significantly higher than that of other age groups (7). Young people tend to accept and try new things readily, especially when they were recommended by friends. This study demonstrated that most EC users came into contact with an EC for the first time through introduction by friends or relatives. Furthermore, most EC users often had a higher education level compared with traditional cigarette smokers (7).

At present, the ECs on the market come as prefilled cartridge systems and refill systems (10). A pre-filled EC is an integrated system, which consists of a receptacle prefilled with EC liquid, batteries, and an atomizer. Components of a pre-filled EC are not replaceable, and the unit is disposable. Refillable units can be re-filled with EC liquid by the user. These re-usable units are easy to use and relatively low in price, making them first choice for more than $90 \%$ of all users. Unlike traditional cigarettes, ECs have a variety of flavors, providing a pleasant experience for users and, in turn, a sense of increasing satisfaction and fun. SOULE et al. surveyed 114 of the most popular flavors (11). Flavor was grouped into four categories: food/desserts/spices (36.8\%), fruit $(36.0 \%)$, tobacco or menthol $(14.9 \%)$, and others or a combination of flavors $(12.3 \%)$. Our study found that the majority of users preferred fruit and food flavors.

People who use ECs are predominantly dual users. Further, those who smoke traditional cigarettes are more likely to use ECs as well. ECs can attract non-smokers to try ECs. In particular, the adults using ECs claimed that the craving for nicotine would be alleviated, and they could use ECs where smoking was not allowed or use them to quit smoking. Users have identified ECs as a means to have access to vaping at any time, with an added benefit of limitless flavors (12). A survey of 46 traditional cigarette users found that approximately three out of four people surveyed admitted to use ECs on all 30 days of the month past (11). The data suggested that the most important reasons to start using ECs were to reduce or completely quit smoking (74.8\%) and to reduce the exposure of family members to second-hand smoke. Some studies also found that smoking cessation or reduction was the primary reason for using ECs (13-16). These studies are consistent throughout the current amount of knowledge on this topic. The second most frequent purpose of use was to reduce health risks $(13,14)$. Other frequently cited factors for selecting ECs were the lower costs compared to that of traditional ciga- rettes as well as the public smoking ban $(17,18)$.

The symptoms of a dry mouth and throat were reported by our study participants, which may be associated with the water-absorbing properties of propylene glycol and glycerol, the main constituents of the EC liquid. Typically, users have defined these side effects as minimal when compared with the other physiological benefits (19-21).

Our survey also found that $74.6 \%$ of the users believed that EC use was not irritating to the mouth. One study of 19,000 users found that more than $90 \%$ of traditional cigarette smokers felt an improvement or static changes to their adverse respiratory effects (pharyngitis, cough, and irritation, etc.) and other physical health conditions when switching to ECs (22). These results are consistent with our findings in this study. Moreover, most participants' families expressed support or no adverse opinion about EC use. A longitudinal study conducted by ETTER and BULLEN found that $46 \%$ of dual users quit smoking successfully after a year of follow-up (23).

Overall, this EC population survey demonstrates that young people are the main users of ECs. A great variety of flavors in ECs attracts people of all ages. The perceived characteristics of ECs, such as stylishness and fun, can attract smokers to choose ECs. With dual users, the use of ECs may reduce their use of traditional cigarettes and encourage them to choose cigarettes with lower nicotine concentrations. Most smokers considered that ECs could be used in no-smoking environments and that they lower the harm risk to family members.

\section{ACKNOWLEDGEMENT}

This work was supported by the China National Tobacco Corporation Standard Project Study on Smoking Behavior and Exposure Risk of E-Cigarette Consumers 2018QBZ04, and the China Tobacco Yunnan Industrial Co. Ltd. Project Study on Short-Term Inhalation Exposure of Non-Combustible Tobacco Products and E-Cigarettes by Electric Heating and Non-Combustible Cigarettes and E-Cigarettes FW321050101SC1ZL.

\section{REFERENCES}

1. Framework Convention Alliance (FCA): FCA Policy Briefing. Electronic Nicotine Delivery Systems; Presented at the Sixth Session of the Conference of the Parties to the WHO Framework Convention on Tobacco Control, 13-18 October 2014, Moscow, Russia. Available at: https://www.fctc.org/fca-policy-briefingelectronic-nicotine-delivery-systems/ (accessed July, 2021)

2. Hammond, D., J.L. Reid, A.G. Cole, and S.T. Leatherdale: Electronic Cigarette Use and Smoking Initiation Among Youth: A Longitudinal Cohort Study; Can. Med. Assoc. J. 189 (2017) E1328-E1336.

DOI: $10.1503 /$ cmaj.161002

3. Reid, J.L., V.L. Rynard, C.D. Czoli, and D. Hammond: Who is Using E-Cigarettes in Canada? Nationally Representative Data on the Prevalence of E-Cigarette Use Among Canadians; Prev. Med. 81 (2015) 180-183. DOI: 10.1016/j.ypmed.2015.08.019 
4. Barnett, T.E., E.K. Soule, J.R. Forrest, L. Porter, and S.L. Tomar: Adolescent Electronic Cigarette Use: Associations with Conventional Cigarette and Hookah Smoking; Am. J. Prev. Med. 49 (2015) 199-206. DOI: $10.1016 /$ j.amepre.2015.02.013

5. Barrington-Trimis, J.L., R. Urman, A.M. Leventhal, W.J. Gauderman, T.B. Cruz, T.D. Gilreath, S. Howland, J.B. Unger, K. Berhane, J.M. Samet, and R. McConnell: E-Cigarettes, Cigarettes, and the Prevalence of Adolescent Tobacco Use; Pediatrics 138 (2016) e20153983. DOI: 10.1542/peds.2015-3983

6. Li, S.S., D. Xiao, S.L. Chu, H.Y. Qin, and C. Wang: Investigation on the Use of E-Cigarettes among cigarette smokers in Beijing; Chin. Clin. J. 43 (2015) 47-99. [in Chinese] DOI: 10.3969/j.issn.2095-8552.2015.03.015

7. Li, W., G. Jiang, Z. Xu, W. Zheng, W. Shen, X. Xue, and Y. Yang: Analysis on the Results of the Investigation on the Use of Electronic Cigarettes by Urban Residents in Tianjin; Chin. J. Prev. Contr. Chron. Dis. 24 (2016) 509-511. Avaliable at: http://caod.oriprobe. com/articles/49020937/tian_jin_shi_cheng_shi_ju_min_ dian_zi_yan_shi_yong_qing_kuang_diao_cha.htm

8. Lee, J.A., S. Lee, and H.J. Cho: The Relation between Frequency of E-Cigarette Use and Frequency and Intensity of Cigarette Smoking Among South Korean Adolescents; Int. J. Environ. Res. Public Health. 14 (2017) 305. DOI:10.3390/ijerph14030305

9. Dai H. and J. Hao: Flavored Electronic Cigarette Use and Smoking Among Youth; Pediatrics 138 (2016) e20162513-e20162513. DOI:10.1542/peds.2016-2513.

10.Berg, C.J.: Preferred Flavors and Reasons for ECigarette Use and Discontinued Use Among Never, Current, and Former Smokers; Int. J. Public Health 2 (2016) 225-236. DOI: 10.1007/s00038-015-0764-X

11.Soule, E.K., A.A. Lopez, M.C. Guy, and C.O. Cobb: Reasons for Using Flavored Liquids Among Electronic Cigarette Users: A Concept Mapping Study; Drug Alcohol Depend. 166 (2016) 168-176. DOI: 10.1016/j.drugalcdep.2016.07.007

12.Kim, H., A.H. Davis, J.L. Dohack, and P.I. Clark: ECigarettes Use Behavior and Experience of Adults: Qualitative Research Findings to Inform E-Cigarette Use Measure Development; Nicotine Tob. Res. 19 (2017) 190-196. DOI: 10.1093/ntr/ntw175

13.Adkison, S.E., R.J. O’Connor, M. Bansal-Travers, A. Hyland, R. Borland, H.H. Yong, K.M. Cummings, A. McNeill, J.F. Thrasher, D. Hammond, and G.T. Fong: Electronic Nicotine Delivery Systems: International Tobacco Control Four-Country Survey; Am. J. Prev. Med. 44 (2013) 207-215. DOI: 10.1016/j.amepre

14.Berg, C.J., R. Haardoerfer, C. Escoffery, P. Zheng, and M. Kegler: Cigarette Users' Interest in Using or Switching to Electronic Nicotine Delivery Systems for Smokeless Tobacco for Harm Reduction, Cessation, or Novelty: A Cross-Sectional Survey of US Adults; Nicotine Tob. Res. 17 (2015) 245-255.

DOI: $10.1093 /$ ntr/ntu103
15.Brown, J., R. West, E. Beard, S. Michie, L. Shahab, and A. McNeill: Prevalence and Characteristics of ECigarette Users in Great Britain: Findings From a General Population Survey of Smokers; Addict. Behav. 39 (2014) 1120-1125.

DOI: $10.1016 /$ j.addbeh.2014.03.009

16. Goniewicz, M.L., E.O. Lingas, and P. Hajek: Patterns of Electronic Cigarette Use and User Beliefs About Their Safety and Benefits: An Internet Survey; Drug Alcohol Rev. 32 (2013) 133-140.

DOI: $10.1111 /$ j.1465-3362.2012.00512.x

17.Kadimpati, S., M. Nolan, and D.O. Warner: Attitudes, Beliefs, and Practices Regarding Electronic Nicotine Delivery Systems in Patients Scheduled for Elective Surgery; Mayo. Clin. Proc. 90 (2015) 71-76. DOI: 10.1016/j.mayocp.2014.11.005

18.Soule, E.K., S.R. Rosas, and A. Nasim: Reasons for Electronic Cigarette Use Beyond Smoking Cessation: A Concept Mapping Approach; Addict. Behav. 56 (2016) 41-50. DOI: 10.1016/j.addbeh.2016.01.008

19.Farsalinos, K.E., G. Romagna, D. Tsiapras, S. Kyrzopoulos, and V. Voudris: Evaluating Nicotine Levels Selection and Patterns of Electronic Cigarette Use in a Group of "Vapers" who had Achieved Complete Substitution of Smoking; Subst. Abuse 3 (2013) 139-46. DOI: 10.4137/SART.S12756. 6

20.Dawkins, L., J. Turner, A. Roberts, and K. Soar: 'Vaping' Profiles and Preferences: An Online Survey of Electronic Cigarette Users; Addiction 108 (2013) 1115-1125. DOI: 10.1111/add.12150

21.Etter, J.F. and C. Bullen: Electronic Cigarette: Users Profile, Utilization, Satisfaction and Perceived Efficacy; Addiction 106 (2011) 2017-2028.

DOI: $10.1111 / \mathrm{j} .1360-0443.2011 .03505 . \mathrm{x}$

22.Farsalinos, K.E., G. Romagna, D. Tsiapras, S. Kyrzopoulos, and V. Voudris: Characteristics, Perceived Side Effects and Benefits of Electronic Cigarette Use: A Worldwide Survey of More than 19,000 Consumers; J. Environ. Res. Public Health 11 (2014) 4356-4373. DOI: 10.3390/ijerph110404356

23.Etter, J.F. and C. Bullen: A Longitudinal Study of Electronic Cigarette Users; Addict. Behav. 39 (2014) 491-494. DOI: 10.1016/j.addbeh.2013.10.028

24.Vaughan, L. and Y. Chen: Data Mining From Web Search Queries: A Comparison of Google Trends and Baidu Index; J. Assn. Inf. Sci. Tec. 66 (2015) 13-22. DOI: 10.1002/asi.23201

\section{Corresponding author:}

Fuwei Xie

Zhengzhou Tobacco Research Institute of CNTC

No. 2 Fengyang Road, Zhengzhou City

Henan Province

P.R. China

E-mail:xiefuwei@sina.com 